\title{
CARACTERIZAÇÃO DE SOLOS EM UMA TOPOCLIMOSSEQUÊNCIA NO MACIÇO DE TRIUNFO - SERTÃO DE PERNAMBUCO(1)
}

\author{
Rômulo Vinícius Cordeiro Conceição de Souza ${ }^{(2)}$, Mateus Rosas \\ Ribeiro $^{(3)}$, Valdomiro Severino de Souza Junior ${ }^{(4)}$, Marcelo \\ Metri Corrêa ${ }^{(5)}$, Maria da Conceição de Almeida ${ }^{(2)}$, Milton \\ César C. Campos ${ }^{(2)}$, Mateus Rosas Ribeiro Filho(4) \& Sheila \\ Maria Bretas Bittar Schulze ${ }^{(4)}$
}

\begin{abstract}
RESUMO
Os brejos de altitude nordestinos constituem uma disjunção da mata atlântica, formando ilhas de floresta úmida em plena região semiárida, tendo uma condição climática bastante atípica, favorecida pela ocorrência de chuvas orográficas, com precipitação pluvial que pode atingir valores superiores a $1.200 \mathrm{~mm}$ por ano. No Estado de Pernambuco, a maioria dos estudos em brejos de altitude abrange os aspectos botânicos e faunísticos, sendo, portanto, importante a realização de estudos para caracterização dos recursos edáficos. Com intuito de estudar os solos de brejos de altitude no Sertão Pernambucano e avaliar a influência dos diversos fatores pedogenéticos na sua formação e evolução, foi feita a caracterização morfológica, física, química e mineralógica de três perfis no maciço de Triunfo, em diferentes altitudes, localizados nos municípios de Serra Talhada (P1), Santa Cruz da Baixa Verde (P2) e Triunfo (P3), formando uma topoclimossequência. Os perfis estudados apresentam características morfológicas similares, relacionadas com o pequeno grau de desenvolvimento pedogenético, principalmente nos perfis P3 (Triunfo) e P2 (Santa Cruz), classificados, respectivamente, como Cambissolo Háplico Tb Eutrófico latossólico e Cambissolo Háplico Tb Eutrófico típico. O perfil P1 (Serra Talhada), localizado no sopé, apresentou menor teor de argila e acentuado gradiente textural, resultante de descontinuidade litológica, sendo classificado como Argissolo Vermelho-Amarelo distrófico abrúptico (cambissólico). Todos os
\end{abstract}

\footnotetext{
(1) Trabalho extraído da Dissertação de Mestrado do primeiro autor apresentada ao Programa de Pós-Graduação em Ciência do Solo, Universidade Federal Rural de Pernambuco - UFRPE. Recebido para publicação em maio de 2009 e aprovado em maio de 2010.

(2) Doutorando do Programa de Pós-Graduação em Ciência do Solo, Universidade Federal Rural de Pernambuco - UFRPE. CEP 52171-900 Recife (PE). E-mail: rvccsouza@yahoo.com.br

(3) Professor do Departamento de Agronomia, UFRPE. Bolsista do CNPq. E-mail: mateus.rosas@pq.cnpq.br

(4) Professor do Departamento de Agronomia, UFRPE. E-mail: valdomiro@depa.ufrpe.br; mateusrf@depa.ufrpe.br; schulze@depa.ufrpe.br

(5) Professor da Unidade Acadêmica de Garanhuns, UFRPE. E-mail: marcelometri@yahoo.com
} 
solos deste estudo são oriundos de rochas sieníticas, sendo, pelo menos em parte, influenciados pelo transporte e pela deposição de materiais oriundos da parte superior do relevo. O perfil de Triunfo, em local mais úmido, apresentou o maior grau de desenvolvimento em relação aos demais. $O$ clima, atuando principalmente pela variação de umidade, não foi, entretanto, o único fator de formação responsável pela diferenciação dos solos ao longo da topoclimossequência, devendo-se ressaltar, também, a influência do material de origem e do relevo.

Termos de indexação: Cambissolos, Argissolos, brejos de altitude, pedogênese, óxidos de ferro.

\title{
SUMMARY: SOIL CHARACTERIZATION ALONG A CLIMATIC GRADIENT IN THE TRIUNFO MOUNTAIN RANGE, SEMI-ARID REGION OF PERNAMBUCO STATE, BRAZIL
}

\begin{abstract}
Highland forests in mountains of Northeast Brazil are islands of humid Atlantic forest in the midst of the semi-arid region. The climatic conditions are rather atypical, improved by the occurrence of orographic rainfall, which can reach 1,200 $\mathrm{mm}$ per year. In the state of Pernambuco, most of the scientific studies in these humid highland forests are focused on botanical and zoological aspects only, with very little information about soils. Aiming to study the soils of the humid mountains in the semi-arid region and to evaluate the influence of the various soil-forming factors on formation and evolution, three soil profiles were characterized for morphological, physical, chemical, and mineralogical properties in the Triunfo mountain range, at different altitude levels. The soil profiles were located in the municipalities of Serra Talhada (P1), Santa Cruz da Baixa Verde (P2) and Triunfo (P3), along a moisture and altitude gradient (topo-climatic sequence). The soils were morphologically similar, due to the low development degree, mainly in the soil profiles P3 (Triunfo) and P2 (Santa Cruz), classified, respectively, as Oxic Haplustept and Typic Haplustept. In the lower part of profile P1 (Serra Tallhada), a low clay content and greater textural gradient classified the soil as Typic Haplustult. The results showed that all studied soils were developed from syenitic rocks, with influence of sediments from the upper part of the relief. The development degree of the soil of Triunfo, with the highest rainfall levels, was higher than of the others. Climate, acting mainly by the variation in moisture, was however not the only soil forming factor responsible for soil differentiation along the sequence, but parent material and relief were important as well.
\end{abstract}

Index terms: inceptisols, humid highland forest, pedogenesis, iron oxides.

\section{INTRODUÇÃO}

Em meio às condições de aridez do sertão nordestino, são observadas "ilhas de umidade", com vegetação exuberante, os chamados "Brejos de Altitude", que quebram a monotonia das condições físicas e biológicas da região semiárida. Os brejos de altitude nordestinos representam uma disjunção da mata atlântica, formando ilhas de floresta úmida em plena região semiárida, tendo uma condição climática bastante atípica (Andrade-Lima, 1982; Tabarelli \& Santos, 2004).

Essas florestas são circundadas pela região semiárida, onde a precipitação pluvial média anual não ultrapassa 900 mm (Lins, 1989), e estão associadas à ocorrência de serras, planaltos e chapadas, com altitudes entre 500 e $1.100 \mathrm{~m}$, o que favorece a ocorrência de chuvas orográficas, que chegam a atingir valores superiores a $1.200 \mathrm{~mm}$ por ano (AndradeLima, 1960). Os brejos de altitude possuem, portanto, condições privilegiadas quanto à umidade do solo e do ar, temperatura e cobertura vegetal, quando comparados à região semiárida circundante (AndradeLima, 1966).

No Estado de Pernambuco, a maioria dos estudos em brejos de altitude abrange os aspectos botânicos e faunísticos, como aqueles realizados por Rodal et al. (2005), Ferraz \& Rodal (2006) e Silva et al. (2007). A despeito da importância desses aspectos para a caracterização e conservação desses ambientes, ressalta-se a importância da realização de estudos para caracterização física, química, morfológica e mineralógica dos solos, visando compreender os processos relacionados à sua gênese. Essas 
informações constituirão a base dos conhecimentos para subsidiar o emprego de técnicas para o uso e manejo sustentável desses solos, além de integrar uma base de dados que poderá auxiliar futuros planos de recuperação de áreas degradadas.

Com o intuito de estudar solos dos brejos de altitude no Sertão Pernambucano e avaliar a influência dos diversos fatores pedogenéticos na sua formação e evolução, foi feita a caracterização morfológica, física, química e mineralógica de três perfis na região do maciço de Triunfo, em diferentes altitudes, constituindo uma topoclimossequência.

\section{MATERIAL E MÉTODOS}

\section{Área de estudo}

A escolha dos locais para a coleta dos perfis foi feita em visitas preliminares e em observância ao gradiente de altitude e umidade - esta, com base na observação da vegetação e do uso atual (Figura 1). A seleção dos pontos para a abertura das trincheiras foi feita por meio de tradagens e consultas a mapas geológicos, na tentativa de uniformizar, dentro do possível, o material de origem (Quadro 1).

As descrições dos perfis e a coleta das amostras por horizonte foram realizadas conforme as recomendações de Santos et al. (2005). Foram coletadas amostras deformadas de todos os horizontes e amostras indeformadas de horizontes selecionados.

\section{Análises físicas e químicas}

As análises foram realizadas, com três repetições, de acordo com métodos descritos pela Embrapa (1997). As análises físicas incluíram: granulometria, com determinação de argila+silte e argila pelo método da pipeta (Ruiz, 2005); argila dispersa em água; densidade do solo (cilindro volumétrico) e das partículas; e porosidade total (calculada a partir dos dados de Ds e Dp). As análises químicas incluíram as determinações de: $\mathrm{pH}$ em água e $\mathrm{KCl} 1 \mathrm{~mol} \mathrm{~L}-1(1: 2,5) ; \mathrm{Ca}^{2+} \mathrm{e} \mathrm{Mg}^{2+}$ (extraídos com $\mathrm{KCl} 1 \mathrm{~mol} \mathrm{~L}^{-1}$ e determinados por espectrofotometria de absorção atômica); $\mathrm{Na}^{+}$e $\mathrm{K}^{+}$ (extraídos com solução de Mehlich-1 e determinados por espectrofotometria de chama); $\mathrm{Al}^{3+}$ (extraído com solução de $\mathrm{KCl} 1 \mathrm{~mol} \mathrm{~L}^{-1}$ e determinado por titulação com $\mathrm{NaOH}$ ); $\mathrm{H}+\mathrm{Al}$ (extraídos com solução de acetato

Quadro 1. Localização e descrição simplificada dos locais dos perfis estudados

\begin{tabular}{|c|c|c|c|c|c|c|c|c|}
\hline Município & $\begin{array}{l}\text { Coord. } \\
\text { Perfil }\end{array}$ & $\begin{array}{l}\text { Temp. } \\
\text { média }\end{array}$ & $\begin{array}{l}\text { Precip. } \\
\text { média }\end{array}$ & Altitude & $\begin{array}{l}\text { Relevo/ } \\
\text { posição }\end{array}$ & Declive & Veg. primária & Veg. local \\
\hline & & ${ }^{\circ} \mathrm{C}$ & $\mathrm{mm}$ & $\mathrm{m}$ & & $\%$ & & \\
\hline $\begin{array}{l}\text { Serra } \\
\text { Talhada (P1) }\end{array}$ & $\begin{array}{l}07^{\circ} 54^{\prime} \mathrm{S} \mathrm{e} \\
38^{\circ} 14^{\prime} \mathrm{W}\end{array}$ & 25,2 & 639 & 490 & $\begin{array}{l}\text { suave ondulado/ } \\
\text { sopé }\end{array}$ & 4 & $\begin{array}{l}\text { Caatinga } \\
\text { hiperxerófila }\end{array}$ & $\begin{array}{l}\text { Caatinga } \\
\text { hiperxerófila } \\
\text { secundária }\end{array}$ \\
\hline $\begin{array}{l}\text { Santa Cruz } \\
\text { da Baixa } \\
\text { Verde (P2) }\end{array}$ & $\begin{array}{l}07^{\circ} 52^{\prime} \mathrm{S} \\
38^{\circ} 10^{\prime} \mathrm{W}\end{array}$ & 21,9 & --- & 774 & $\begin{array}{l}\text { forte-ondulado } \\
\text { e montanhoso/ } \\
\text { encosta }\end{array}$ & 25 & $\begin{array}{l}\text { Floresta } \\
\text { caducifólia }\end{array}$ & $\begin{array}{l}\text { Feijão-guandu } \\
\text { e macassar, } \\
\text { milho e fruteiras }\end{array}$ \\
\hline Triunfo (P3) & $\begin{array}{l}07^{\circ} 50^{\prime} \mathrm{S} \\
38^{\circ} 05^{\prime} \mathrm{W}\end{array}$ & 20,4 & 1230 & 1.034 & $\begin{array}{l}\text { forte-ondulado } \\
\text { e montanhoso/topo }\end{array}$ & 16 & $\begin{array}{l}\text { Floresta } \\
\text { subcaducifólia }\end{array}$ & $\begin{array}{l}\text { Cana-de-açúcar, } \\
\text { banana e } \\
\text { fruteiras }\end{array}$ \\
\hline
\end{tabular}

Fonte: ITEP/LAMEPE (2009).

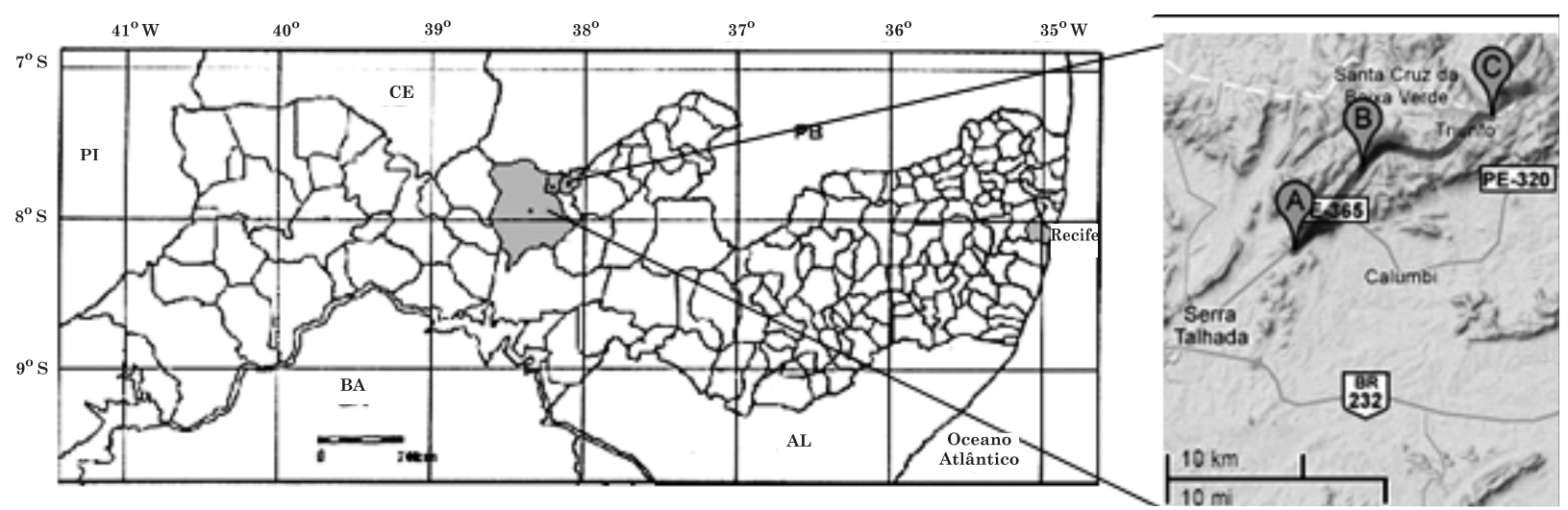

Figura 1. Mapa com a localização das áreas amostradas (Adaptado de Oliveira et al., 2003; Google ${ }^{\circledR}$ Dados Cartográficos, 2010). A: P1, B: P2 e C: P3. 
de cálcio $0,5 \mathrm{~mol} \mathrm{~L}-1$ e determinados por titulação com $\mathrm{NaOH}$ ); P extraível (extraído com solução de Mehlich1 e determinado por colorimetria); e C orgânico (oxidação pelo dicromato de potássio em meio sulfúrico).

\section{Análises mineralógicas e petrográficas}

As frações da TFSA foram separadas por peneiramento úmido (areia) e por sedimentação (silte e argila), para identificação de seus componentes e análise qualitativa por difratometria de raios X(DRX). A fração argila foi analisada em lâminas com argila orientada, após saturação com $\mathrm{K}$, à temperatura ambiente e após aquecimento a $550{ }^{\circ} \mathrm{C}$ por duas horas, depois de saturação com $\mathrm{Mg}$, e após solvatação com etileno glicol, todos segundo Whittig \& Allardice (1986). Foram avaliados ainda por DRX os tipos de óxidos em amostras de argila tratadas com $\mathrm{NaOH} 5 \mathrm{~mol} \mathrm{~L}^{-1}$ (Kämpf \& Schwertmann, 1982, modificado por Singh \& Gilkes, 1991), utilizando-se o método do pó.

Os difratogramas foram obtidos empregando-se difratômetro Shimadzu, operando a uma tensão de $40 \mathrm{kv}$, com corrente de $20 \mathrm{~mA}$, radiação de $\mathrm{Cu} \mathrm{K} \alpha$, com monocromador de grafite. A amplitude de varredura foi de 5 a $70^{\circ}(2 \theta)$ e a velocidade de registro, de $3^{\circ} 2 \theta \mathrm{min}^{-1}$, para areia total e silte; no caso da argila em pó, a amplitude foi de 3 a $70^{\circ}(2 \theta)$, na mesma velocidade. Para as amostras saturadas com $\mathrm{K}$ à temperatura ambiente, aquecidas a $550{ }^{\circ} \mathrm{C}$ e saturadas com etileno glicol, a amplitude de varredura foi de 3 a $35^{\circ}(2 \theta)$ e a velocidade de registro, de $2^{\circ} 2 \theta \mathrm{min}^{-1}$. Nas amostras de concentrado de óxidos, a amplitude de varredura foi de 3 a $70^{\circ}(2 \theta)$ e a velocidade de registro, de $2^{\circ} 2 \theta \mathrm{min}^{-1}$.

Foram analisados também os teores totais dos elementos $\mathrm{Si}$, Al e Fe por ataque sulfúrico na TFSA (Embrapa, 1997).

Para a realização do estudo litológico, foram preparadas seções delgadas das rochas subjacentes aos perfis e presentes como calhaus em alguns horizontes, ao natural, ou impregnadas com resina, nos casos em que a primeira situação não foi possível. As análises foram feitas com o uso de microscópio petrográfico (Murphy, 1986).

\section{RESULTADOS E DISCUSSÃO}

\section{Atributos morfológicos}

Os solos estudados apresentaram feições similares às dos Cambissolos, indicadas pela presença de muitos minerais primários na fração grosseira e de fragmentos de rocha semi-intemperizada ao longo do perfil, com pouca diferenciação entre os horizontes, exceto para o perfil P1. De maneira geral, todos os perfis mostraram pouca variação de cor, com coloração vermelhoamarelada, apresentando mosqueados apenas no horizonte $\mathrm{C}$ do $\mathrm{P} 1$ e $\mathrm{Bi} / \mathrm{Cr}$ do $\mathrm{P} 2$, resultantes do intemperismo de fragmentos da rocha matriz (Quadro 2).

Quadro 2. Características morfológicas dos solos estudados

\begin{tabular}{|c|c|c|c|c|c|c|c|c|}
\hline \multirow{2}{*}{ Horizonte } & \multirow{2}{*}{ Profundidade } & \multicolumn{2}{|c|}{ Cor } & \multirow{2}{*}{ Estrutura } & \multirow{2}{*}{ Seca } & \multicolumn{2}{|c|}{ Consistência } & \multirow{2}{*}{ Transição } \\
\hline & & Úmida & Mosqueado & & & Úmida & Molhada & \\
\hline \multicolumn{9}{|c|}{ Argissolo Vermelho-Amarelo distrófico abrúptico cambissólico (Serra Talhada - P1) } \\
\hline A & $0-15$ & $5 Y R$ 4/4 & -- & $\begin{array}{l}1 \mathrm{P} \text { Gr Bls } \\
\text { Ma p coesa }\end{array}$ & $\mathrm{MD}$ & $\mathrm{Fr}$ & LgPl LgPe & $\mathrm{pg}$ \\
\hline $2 \mathrm{Bt} 1$ & $15-37$ & $5 \mathrm{YR} 4 / 6$ & -- & $1 \mathrm{P} \mathrm{Bls}$ & MD & Fr e Fi & LgPl LgPe & $\mathrm{pg}$ \\
\hline $2 \mathrm{Bt} 2$ & $37-78$ & $5 \mathrm{YR} 5 / 8$ & -- & $1 \mathrm{P} \mathrm{Bls}$ & MD & $\mathrm{Fr}$ & LgPl LgPe & $\mathrm{pg}$ \\
\hline $2 \mathrm{BC}$ & $78-105$ & 7,5YR 5/8 & -- & 1MP P Bls & MD e D & $\mathrm{Fr}$ & Lgpl e Lpg & pc \\
\hline $2 \mathrm{Cr}$ & $105-130$ & $\begin{array}{c}\text { 5YR 4/6 } \\
10 Y R 6 / 6 \\
\text { Cambisso }\end{array}$ & olo Háplico Tb & - & $\begin{array}{l}\text { MD } \\
\text { a Cruz da }\end{array}$ & aixa Verde & P2) & pa \\
\hline $\mathrm{A}$ & $0-15$ & $5 \mathrm{YR} 4 / 6$ & -- & $\begin{array}{l}\text { 1P Bls } \\
\text { Ma p coesa }\end{array}$ & LD e D & $\mathrm{Fr}$ & LgPl LgPe & $\mathrm{pa}$ \\
\hline Bi1 & $15-32$ & $2,5 \mathrm{YR} 4 / 6$ & -- & 1P Bls & $\mathrm{LD}$ & $\mathrm{MFr}$ & LgPl LgPe & $\mathrm{pc}$ \\
\hline $\mathrm{Bi} 2$ & $32-60$ & $5 \mathrm{YR} 5 / 6$ & -- & $1 \mathrm{P} \mathrm{Bls}$ & $\mathrm{MD}$ & $\mathrm{MFr}$ & LgPl LgPe & $\mathrm{pg}$ \\
\hline $\mathrm{Bi} / \mathrm{Cr}$ & $60-140$ & $5 \mathrm{YR} 5 / 6$ & 10YR 6/8 & $1 \mathrm{P} \mathrm{Bls}$ & $\mathrm{MD}$ & $\mathrm{MFr}$ & LgPl LgPe & og \\
\hline \multicolumn{9}{|c|}{ Cambissolo Háplico Tb eutrófico latossólico (Triunfo - P3) } \\
\hline $\mathrm{A}$ & $0-18$ & $5 \mathrm{YR} 3 / 4$ & - & $2 \mathrm{P}$ Gr $1 \mathrm{PBls}$ & $\mathrm{D}$ e $\mathrm{MD}$ & $\mathrm{Fr}$ & LgPl LgPe & oa \\
\hline $\mathrm{BA}$ & $18-39$ & $5 \mathrm{YR} 4 / 4$ & - & $1 \mathrm{P} \mathrm{Bls}$ & $\mathrm{MD}$ & $\mathrm{Fr}$ & $\mathrm{Pl} \mathrm{Pg}$ & $\mathrm{pg}$ \\
\hline $\mathrm{Bi} 1$ & $39-70$ & $5 \mathrm{YR} 4 / 6$ & - & 2 P MP Bls & $\mathrm{MD}$ & $\mathrm{Fr}$ & $\mathrm{Pl} \mathrm{Pg}$ & pd \\
\hline $\mathrm{Bi} 2$ & $70-110$ & $5 \mathrm{YR} 4 / 6$ & - & $1 \mathrm{P} \mathrm{MP} \mathrm{Bls}$ & $\mathrm{MD}$ & $\mathrm{Fr}$ & $\mathrm{Pl} \mathrm{Pg}$ & $\mathrm{pd}$ \\
\hline $\mathrm{BC}$ & $110-170+$ & $5 Y R$ 5/8 & - & $1 \mathrm{P} \mathrm{Bls}$ & $\mathrm{MD}$ & $\mathrm{MFr}$ & $\mathrm{Pl} \mathrm{Pg}$ & -- \\
\hline
\end{tabular}

Estrutura: 1: fraca; 2: moderada; MP: muito pequena; P: pequena; Gr: granular; Bls: blocos subangulares; Ma: maciça. Consistência: LD: ligeiramente dura; D: dura; MD: muito dura; MFr: muito friável; Fr: friável; Fi: firme; Lg: ligeiramente; Pl: plástico; Pe: pegajoso. Transição: p: plana; o - ondulada; a: abrupta; g: gradual; d: difusa; c: clara. 
Foram observadas variações de profundidade do solo com o aumento da precipitação, com o P1 (Serra Talhada) apresentando profundidade entre $100 \mathrm{e}$ $130 \mathrm{~cm}$ até a rocha matriz; o P2 (Santa Cruz), de $140 \mathrm{~cm}$; e o P3 (Triunfo), maior que $170 \mathrm{~cm}$. Embora não se possa afirmar que o aumento da precipitação seja o único fator responsável pelo aumento da profundidade, sua influência é inegável, considerando que outras características morfológicas, físicas e químicas apontam para o maior grau de desenvolvimento dos perfis dos locais mais úmidos da sequência.

$\mathrm{O}$ perfil $\mathrm{P} 1$ apresenta sequência de horizontes A2Bt1-2Bt2-2BC-2Cr-2R, com transições graduais e planas entre os horizontes constituintes do solum, e clara, respectivamente em BC e C. Apresenta calhaus e matacões de rocha na superfície e ao longo de todo o perfil. O perfil P1 foi classificado, segundo o Sistema Brasileiro de Classificação dos Solos - SiBCS (Embrapa, 2006), como Argissolo Vermelho-Amarelo distrófico abrúptico (cambissólico), A fraco, textura média (leve)/média, fase pedregosa, caatinga hiperxerófila, relevo suave ondulado. A presença de muitos cascalhos no horizonte A, a ocorrência de calhaus e matacões arredondados ao longo de todo o perfil e a posição de ocorrência desse solo no sopé da encosta de um maciço montanhoso sugerem que o gradiente textural observado na superfície é mais uma consequência do transporte de materiais do que de processos de eluviação/iluviação de argila. O termo cambissólico, embora não esteja previsto entre os subgrupos dos Argissolos Vermelho-Amarelos pelo SiBCS (Embrapa, 2006), está sendo proposto neste trabalho para indicar solos com propriedades intermediárias para Cambissolos, apresentando grande quantidade de materiais primários alteráveis visíveis no perfil e, ou, fragmentos de rocha no horizonte $\mathrm{B}$, como já previsto para outras ordens do Sistema.

$\mathrm{O}$ perfil $\mathrm{P} 2$, na encosta do maciço, tem sequência de horizontes Ap-Bi1-Bi2-Bi/Cr-R, com transições graduais, exceto no Ap, onde se apresenta clara, e no $\mathrm{Bi} / \mathrm{Cr}$, que tem transição abrupta e ondulada para a rocha (grandes fragmentos). Apresenta como principais diferenças morfológicas, em relação ao P1, a maior profundidade efetiva, a ausência de gradiente textural, a presença de um horizonte Ap, consequência da utilização agrícola, e a presença de um horizonte miscigenado $\mathrm{Bi} / \mathrm{Cr}$, de 60 a $140 \mathrm{~cm}$, constituído de partes semelhantes às do Bi2 sobrejacente, e partes constituídas por fragmentos de rocha, semiintemperizados e com arredondamento característico da alteração pelicular dos sienitos. O solo ocupa uma posição de maior declividade, em meia-encosta de um relevo forte ondulado, sendo bastante alterado pela erosão. As demais características morfológicas (cor, estrutura e consistência) dos três primeiros horizontes dos perfis P1 e P2 são muito semelhantes, demonstrando certa similaridade relacionada com o pequeno grau de desenvolvimento pedogenético. A textura dos horizontes $\mathrm{Bt}$ e Bi dos dois perfis também se enquadra na mesma classe textural. O perfil foi classificado como Cambissolo Háplico Tb eutrófico típico, A moderado, textura média, fase pedregosa e rochosa, floresta caducifólia, relevo forte ondulado, substrato sienito. A declividade acentuada e o processo erosivo acelerado atuante nessa posição de encosta tiveram grande influência na formação e evolução desse solo.

O perfil P3 tem sequência de horizontes Ap-BABi1-Bi2-BC, com cor bruno-avermelhada escura no Ap e vermelho-amarelada ao longo do restante do perfil. Apresenta transição abrupta e ondulada no Ap, gradual no BA e difusa em Bi1 e Bi2, com o BC atingindo $170 \mathrm{~cm}$, sem nenhuma evidência da rocha matriz até esta profundidade. Fragmentos de rocha arredondados foram encontrados apenas no Bi2. Possui textura franco-argilosa no Ap, argila em BA e $\mathrm{Bi}$, voltando a franco-argilosa no BC. Além da maior profundidade efetiva, este solo, localizado próximo ao topo e na parte mais úmida do maciço, apresenta outras características morfológicas que refletem maior grau de desenvolvimento em relação aos demais, como textura mais argilosa, menor quantidade de cascalhos e calhaus ao longo do perfil, estrutura mais desenvolvida e pouca diferenciação entre os horizontes. Em virtude do maior grau de evolução, foi classificado como Cambissolo Háplico Tb eutrófico latossólico, A moderado, textura argilosa, fase floresta subcaducifólia, relevo forte ondulado, substrato sienito.

\section{Atributos físicos}

Com relação à variação das frações granulométricas ao longo da topoclimossequência, observa-se aumento expressivo dos teores de argila e redução dos teores de areia, particularmente de areia grossa, com o aumento da altitude e, em consequência, da maior disponibilidade de água ou do menor déficit hídrico (Quadro 3). Considerando todos os horizontes, os teores de argila variaram entre $104 \mathrm{e} 296 \mathrm{~g} \mathrm{~kg}^{-1}$ no P1, 251 a $315 \mathrm{~g} \mathrm{~kg}^{-1}$ no P2 e 300 a $415 \mathrm{~g} \mathrm{~kg}^{-1}$ no P3. Para a fração areia grossa, a variação foi de 226 a 422,175 a 232 e 66 a $105 \mathrm{~g} \mathrm{~kg}^{-1}$, para os perfis P1, P2 e P3, respectivamente. Esses resultados sugerem a influência da altitude e umidade no aumento do intemperismo.

Os teores de areia fina são similares ao longo dos perfis e os de silte aumentam com a umidade do ambiente, principalmente no perfil do topo, variando de 194 a 285,247 a 285 e 293 a $399 \mathrm{~g} \mathrm{~kg}^{-1}$, respectivamente, em $\mathrm{P} 1, \mathrm{P} 2$ e P3. Os teores de silte são mais altos nos horizontes $\mathrm{A}$, em virtude de perda ou translocação de argila, e nos horizontes $\mathrm{Cr}$ ou BC, pela menor ação do intemperismo. No horizonte B dos perfis, os valores da relação silte/argila são compatíveis com o baixo grau de intemperismo dos Cambissolos, variando entre 0,75 e 0,92. A variação brusca da relação AF/AG entre o A e o Bt do P1 é mais um indício da descontinuidade litológica neste perfil. 
Quadro 3. Características físicas dos solos estudados

\begin{tabular}{|c|c|c|c|c|c|c|c|c|c|c|c|c|c|}
\hline \multirow{2}{*}{ Horizonte } & \multirow{2}{*}{ Profundidade } & \multicolumn{3}{|c|}{ Areia } & \multirow{2}{*}{ Silte } & \multirow{2}{*}{ Argila } & \multirow{2}{*}{$\mathrm{ADA}^{(1)}$} & \multirow{2}{*}{$\mathbf{G F}^{(1)}$} & \multirow{2}{*}{ Silte/argila } & \multirow{2}{*}{$\mathrm{AF} / \mathrm{AG}^{(1)}$} & \multirow{2}{*}{ Ds } & \multirow{2}{*}{ Dp } & \multirow{2}{*}{ Poros $^{(1)}$} \\
\hline & & Grossa & Fina & Total & & & & & & & & & \\
\hline & $\mathrm{cm}$ & 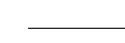 & . & g l & $\mathrm{g}^{-1}$ & & - & $\%$ & & & $-\mathrm{gc}$ & $\mathrm{n}^{-3}-$ & $\%$ \\
\hline \multicolumn{14}{|c|}{ Argissolo Vermelho-Amarelo distrófico abrúptico cambissólico (Serra Talhada - P1) } \\
\hline $\mathrm{A}$ & $0-15$ & 421 & 264 & 685 & 194 & 121 & 54 & 55 & 1,60 & 0,63 & 1,44 & 2,52 & 43 \\
\hline $2 \mathrm{Bt} 1$ & $15-37$ & 269 & 280 & 549 & 197 & 254 & 87 & 66 & 0,77 & 1,04 & 1,55 & 2,67 & 42 \\
\hline $2 \mathrm{Bt} 2$ & $37-78$ & 228 & 232 & 460 & 264 & 276 & 16 & 94 & 0,96 & 1,03 & 1,30 & 2,63 & 51 \\
\hline $2 \mathrm{BC}$ & $78-105$ & 227 & 254 & 481 & 223 & 296 & 8 & 97 & 0,75 & 1,12 & -- & -- & -- \\
\hline $2 \mathrm{Cr}$ & $105-130$ & 380 & 231 & 611 & 285 & 104 & 10 & 90 & 2,74 & 0,61 & -- & -- & -- \\
\hline \multicolumn{14}{|c|}{ Cambissolo Háplico Tb eutrófico típico (Santa Cruz da Baixa Verde - P2) } \\
\hline Ap & $0-15$ & 219 & 258 & 477 & 247 & 276 & 129 & 53 & 0,89 & 1,18 & 1,19 & 2,60 & 54 \\
\hline Bi1 & $15-32$ & 191 & 244 & 435 & 250 & 315 & 70 & 78 & 0,79 & 1,28 & 1,17 & 2,61 & 55 \\
\hline $\mathrm{Bi} 2$ & $32-60$ & 176 & 232 & 408 & 285 & 307 & 6 & 98 & 0,92 & 1,33 & 1,28 & 2,61 & 51 \\
\hline $\mathrm{Bi} / \mathrm{Cr}$ & $60-140$ & 233 & 234 & 467 & 282 & 251 & 9 & 96 & 1,12 & 1,01 & 1,32 & 2,63 & 50 \\
\hline \multicolumn{14}{|c|}{ Cambissolo Háplico Tb eutrófico latossólico (Triunfo - P3) } \\
\hline $\mathrm{Ap}$ & $0-18$ & 106 & 197 & 301 & 399 & 300 & 193 & 36 & 1,33 & 1,88 & 1,39 & 2,69 & 48 \\
\hline $\mathrm{BA}$ & $18-39$ & 73 & 179 & 251 & 334 & 415 & 145 & 65 & 0,80 & 2,45 & 1,29 & 2,60 & 50 \\
\hline Bi1 & $39-70$ & 73 & 183 & 256 & 340 & 404 & 16,5 & 96 & 0,84 & 2,51 & 1,17 & 2,72 & 57 \\
\hline $\mathrm{Bi} 2$ & $70-110$ & 88 & 233 & 321 & 293 & 386 & 8,8 & 98 & 0,75 & 2,65 & 1,21 & 2,74 & 56 \\
\hline $\mathrm{BC}$ & $110-170+$ & 66 & 193 & 259 & 391 & 350 & 14,8 & 96 & 1,11 & 2,92 & 1,29 & 2,58 & 50 \\
\hline
\end{tabular}

(1) ADA: argila dispersa em água; GF: grau de floculação; AF/AG: relação areia fina/areia grossa; Ds: densidade do solo; Dp: densidade de partículas; Poros: porosidade total.

Os valores de densidade do solo são mais elevados no $\mathrm{P} 1$, variando entre $1,44,1,55$ e $1,30 \mathrm{~g} \mathrm{~cm}^{-3}$, nos horizontes A, Bt1 e Bt2, respectivamente. Esses valores são consequência dos menores teores de argila e das maiores percentagens de areia grossa e cascalho, motivo pelo qual não foram retirados anéis volumétricos dos horizontes $\mathrm{BC}$ e $\mathrm{Cr}$ deste perfil. Nos perfis P2 e P3, os valores da densidade do solo variaram entre 1,17 e 1,39, com tendência natural de aumento com a profundidade, exceto nos dois primeiros horizontes do P3, que apresentaram valores mais altos $(1,39)$ em virtude do cultivo da cana.

\section{Atributos químicos}

O P1 e P2 apresentam reação de forte a moderadamente ácida, enquanto o P3 tem reação praticamente neutra (Quadro 4). Nos dois primeiros perfis houve redução do $\mathrm{pH}$ em profundidade, enquanto no P3 ocorreu o inverso. Tendo em vista que as áreas são cultivadas em sistemas de manejo de baixo nível tecnológico, sem aplicação de corretivos e fertilizantes, pode-se supor que essas diferenças no pH são resultantes de pequenas variações na composição do material de origem ou motivadas pela posição no relevo, a qual influencia nos processos de perdas e aportes de materiais na superfície.

$\mathrm{O} \Delta \mathrm{pH}$ é negativo em toda a sequência, caracterizando solos eletronegativos. A baixa CTC e o $\Delta \mathrm{pH}$ negativo são características de solos com mineralogia caulinítica (Mekaru \& Uehara, 1972).

Em nenhum dos perfis os teores de $\mathrm{Mg}$ foram superiores aos de $\mathrm{Ca}$. Os valores de $\mathrm{Mg}$ são baixos, entre 0,2 e $0,5 \mathrm{cmol}_{\mathrm{c}} \mathrm{kg}^{-1}$, no P1; médios, entre 0,6 e
$0,7 \mathrm{cmol}_{\mathrm{c}} \mathrm{kg}^{-1}$, no P2; e médios a altos, entre $0,6 \mathrm{e}$ $1,3 \mathrm{cmol}_{\mathrm{C}} \mathrm{kg}^{-1}$, no P3. Apenas o P3 apresentou valores próximos aos reportados no perfil $69 \mathrm{PE}(0,9-$ $\left.1,5 \mathrm{cmol}_{\mathrm{c}} \mathrm{kg}^{-1}\right)$ - Cambissolo eutrófico latossólico, descrito também em Triunfo - do Levantamento de Solos de Pernambuco (Brasil, 1972). Os valores mais altos encontrados no ambiente de maior precipitação do P3 são, provavelmente, determinados pela natureza mais rica do material de origem.

Apesar de a mineralogia dos solos estudados indicar a presença de feldspatos, os teores de K e Na nos três perfis estudados são predominantemente baixos, inferiores a 0,13 $\mathrm{cmol}_{\mathrm{c}} \mathrm{kg}^{-1}$. Melo et al. (1995a), estudando Cambissolos originados de rochas graníticas no Rio Grande do Sul, ricas em feldspato e mica, observaram que os valores de $\mathrm{K}^{+}$disponível variaram entre 0,02 e $0,24 \mathrm{cmol}_{\mathrm{c}} \mathrm{kg}^{-1}$. Um ambiente com temperaturas mais elevadas e precipitações de menor magnitude, porém com grande intensidade durante algumas épocas do ano, são possíveis razões para justificar os valores mais baixos do $\mathrm{K}^{+}$trocável na área do estudo. Conforme Mielniczuk (1977), em ambientes com elevadas temperaturas, precipitações e boa drenagem, o feldspato se transforma diretamente em caulinita e o $\mathrm{K}^{+}$é facilmente lixiviado. Ainda segundo esse autor, os teores de feldspato na fração silte são maiores nas formas estruturais do que na forma trocável e, pela grande estabilidade, são mais difíceis de ser transformados em formas mais disponíveis.

A soma de bases (SB), de maneira geral, decresceu em profundidade, acompanhando a redução dos teores de matéria orgânica; os maiores valores foram observados no perfil de Triunfo, mais argiloso, com 
Quadro 4. Caracterização química dos perfis estudados

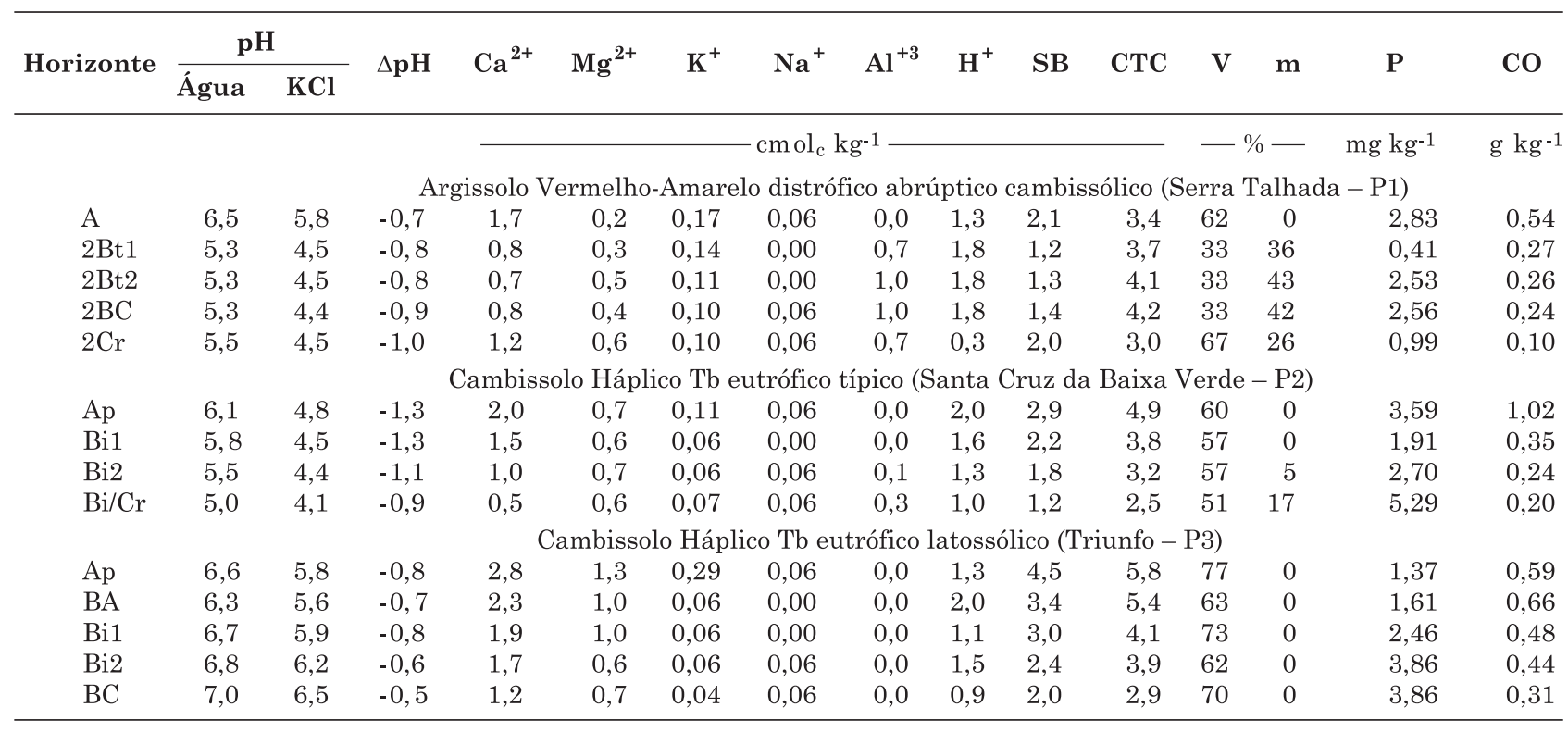

maior CTC e que apresenta níveis mais elevados de Ca e, principalmente, de Mg. O perfil 69 PE (Brasil, 1972) apresentou a mesma tendência de decréscimo da SB em profundidade - consequência da ciclagem de nutrientes promovida pela vegetação. Os valores da soma de bases variaram de 2,2 a 1,3 no P1, de 2,9 a 1,2 no P2 e de 4,5 a 2,0 $\mathrm{cmol}_{\mathrm{c}} \mathrm{kg}^{-1}$ no P3.

$\mathrm{A}$ acidez trocável, representada pelo $\mathrm{Al}^{3+}$, foi praticamente nula nos perfis 2 e 3 , mas no P1 os horizontes subsuperficiais apresentaram valores elevados em relação aos demais. Esse fato não é comum em solos do semiárido. Menezes et al. (2005), discutindo sobre a fertilidade dos solos do semiárido, fizeram uma compilação das principais características químicas da camada superficial de várias classes de solos, em que, dos 49 Cambissolos citados, $96 \%$ apresentaram baixos teores de $\mathrm{Al}^{3+}\left(<0,3 \mathrm{cmol}_{\mathrm{c}} \mathrm{kg}^{-1}\right)$, $4 \%$ com teores médios $\left(0,3-0,8 \mathrm{cmol}_{\mathrm{c}} \mathrm{kg}^{-1}\right)$ e nenhum com teores altos. Esses teores podem ser resultantes da decomposição do material de origem: rochas sieníticas, que, segundo Ferreira \& Sial (1986), apresentam de 13 a $15 \%$ de $\mathrm{Al}_{2} \mathrm{O}_{3}$ em sua composição. Por sua vez, as análises petrográficas mostraram que as rochas formadoras do material de origem do perfil P1 têm natureza mais ácida e são pobres em elementos básicos.

A capacidade de troca de cátions (CTC) acompanhou a mesma tendência da soma de bases em P2 e P3, diminuindo em profundidade com a redução da matéria orgânica, enquanto no $\mathrm{P} 1$ se comportou de maneira inversa, aumentando com a profundidade, com o incremento dos teores de $\mathrm{Al}^{3+}$, que foram maiores neste perfil. A CTC foi maior nos horizontes superficiais de P2 e P3, enquanto no P1 foi mais elevada nos horizontes Bt e BC. Conforme
Corrêa (2005), valores em torno de $5 \mathrm{cmol}_{\mathrm{c}} \mathrm{kg}^{-1}$ refletem a mineralogia caulinítica dos solos. Dessa forma, a CTC é muito influenciada pela matéria orgânica do solo. A atividade da fração argila calculada no B foi baixa em todos os perfis, sendo compatível com uma mineralogia predominantemente caulinítica.

Tanto o perfil P2 como o P3 são eutróficos, com valores da saturação por bases (V \%) variando, respectivamente, entre 51 e $60 \%$ e 61 e $77 \%$. Os valores mais altos correspondem aos horizontes superficiais, em consequência da ciclagem de nutrientes. O P1, a despeito do clima mais seco, foi classificado como distrófico, com V de $33 \%$ no Bt, $62 \%$ no A e $67 \%$ no C. A baixa presença de bases trocáveis no Bt do perfil do ambiente mais seco pode ser explicada pela natureza do material de origem, formado com a contribuição de rochas graníticas, como pode ser observado pela análise petrográfica de rochas coletadas neste horizonte. Essas rochas são de natureza mais pobre do que a rocha do embasamento e também influenciaram a textura mais arenosa deste solo em relação aos demais. A percentagem de saturação por $\mathrm{Al}$ teve valores expressivos apenas no $\mathrm{P} 1$ e nos horizontes $\mathrm{Bi}$ e $\mathrm{Bi} / \mathrm{CR}$ do $\mathrm{P} 2$, porém com valores menores que $50 \%$.

A disponibilidade de $\mathrm{P}$ nos solos estudados está entre baixa e muito baixa, com teores variando de 0,41 a $5,29 \mathrm{mg} \mathrm{dm}^{-3}$. A deficiência de $\mathrm{P}$ é provavelmente mais associada com a reduzida disponibilidade das formas lábeis do que com os valores totais de P. Para os solos da região semiárida do Nordeste brasileiro, estudos mostram a existência de quantidades variáveis da fração lábil de P (Araújo et al., 2004). 
Diversos autores, a exemplo de Oliveira et al. (2003), consideram valores menores que $10 \mathrm{~g} \mathrm{~kg}^{-1}$ como baixos teores de $\mathrm{C}$ orgânico, sendo compatíveis com o uso dos solos e com as condições climáticas reinantes na região semiárida. Os teores de $\mathrm{C}$ orgânico nos solos estudados foram baixos, observando-se, entretanto, que os maiores valores foram encontrados no horizonte $\mathrm{A}$ do P2 e, como um todo, no P3, ambos cultivados. Esses valores mais elevados em P3 são consequência tanto do manejo diferenciado da cultura da cana-de-açúcar no município de Triunfo, onde, após o corte, a palhada é mantida sobre o solo como forma de proteção, quanto pela presença de maiores teores de argila, que podem conferir maior proteção coloidal e dificultar a degradação do material orgânico, conforme Bayer \& Mielniczuk (1999). Associado a isso, o clima mais ameno das partes altas favorece a manutenção de teores um pouco mais altos de C do que em Serra Talhada, parte mais baixa e seca, onde, segundo Araújo et al. (2004), os baixos valores de C orgânico são comuns, devido à pequena contribuição da vegetação de caatinga.

O clima e a topografia são reconhecidos como importantes fatores que influenciam o movimento e a dinâmica dos nutrientes no solo (Araújo et al., 2004). Buol et al. (1973) afirmam que, para um mesmo material de origem, embora as taxas de mudança variem, numa climossequência as seguintes generalizações podem ser feitas: o conteúdo de matéria orgânica cresce com o aumento da altitude, enquanto valores de $\mathrm{pH}$ e conteúdos de $\mathrm{Ca}, \mathrm{Mg}$ e $\mathrm{K}$ sofrem redução com esse aumento. No presente estudo, observou-se que apenas os teores de $\mathrm{C}$ orgânico acompanharam esta tendência (excluindo-se o horizonte A do P2), aumentando em direção ao ponto mais alto da sequência. As demais variáveis $(\mathrm{pH}, \mathrm{Ca}$, e $\mathrm{Mg}$ ) não seguiram a tendência de diminuição, aumentando seus valores do ponto mais baixo para o mais alto. Nesse caso, os resultados parecem refletir a influência do material de origem. De acordo com a análise petrográfica, a litologia da parte superior apresenta maior quantidade de minerais máficos, ricos em Ca e Mg, sendo, portanto, rochas mais básicas, enquanto em Serra Talhada o material de origem sofreu influência de material retrabalhado de rochas mais pobres em minerais ferro-magnesianos.

\section{Ataque sulfúrico}

De maneira geral, os valores de $\mathrm{SiO}_{2}, \mathrm{Al}_{2} \mathrm{O}_{3}$ e $\mathrm{Fe}_{2} \mathrm{O}_{3}$ foram menores no solo do ponto mais baixo da topossequência (P1), aumentando até o ponto mais alto (P3), acompanhando o aumento da precipitação pluvial e dos teores de argila (Quadro 5). Em cada perfil, os valores desses elementos foram menores nos horizontes superficiais e aumentaram em profundidade. Nos três perfis, o $\mathrm{Al}_{2} \mathrm{O}_{3}$ mostrou teores mais elevados em relação aos demais componentes.

Andrade et al. (1997) observaram que o material de origem dos solos de uma topossequência sobre rochas cristalinas no Amazonas era heterogêneo, pois a distribuição em profundidade de $\mathrm{SiO}_{2}, \mathrm{Al}_{2} \mathrm{O}_{3}$ e $\mathrm{Fe}_{2} \mathrm{O}_{3}$ era irregular ao longo da sequência. No caso do presente estudo, também houve pequena irregularidade nessa distribuição em profundidade e as análises petrográficas mostraram certa diferenciação quanto à composição do material de origem ao longo da topossequência (Quadro 7).

Com exceção dos horizontes A e C do P1, os demais valores de Ki foram menores que 1,8, observando-se em todos os perfis um decréscimo da superfície até o horizonte diagnóstico subsuperficial, seguido de aumento nos horizontes menos intemperizados: $\mathrm{C} \mathrm{e}$ BC. Verdade (1972), estudando um Argissolo dos EUA

Quadro 5. Teores de $\mathrm{SiO}_{2}, \mathrm{Al}_{2} \mathrm{O}_{3}, \mathrm{Fe}_{2} \mathrm{O}_{3}$ e relação $\mathrm{Ki}$ dos solos estudados

\begin{tabular}{|c|c|c|c|c|}
\hline Horizonte & $\mathrm{SiO}_{2}$ & $\mathrm{Al}_{2} \mathrm{O}_{3}$ & $\mathrm{Fe}_{2} \mathrm{O}_{3}$ & $\mathbf{K i}$ \\
\hline \multicolumn{5}{|c|}{ Argissolo Vermelho-Amarelo distrófico abrúptico cambissólico (Serra Talhada - P1) } \\
\hline A & 38,3 & 30,7 & 17,7 & 2,13 \\
\hline $2 \mathrm{Bt} 1$ & 97,5 & 93,6 & 33,0 & 1,77 \\
\hline $2 \mathrm{Bt} 2$ & 120,0 & 130,6 & 36,0 & 1,56 \\
\hline $2 \mathrm{BC}$ & 87,4 & 90,2 & 33,5 & 1,65 \\
\hline $2 \mathrm{Cr}$ & 116,3 & 97,1 & 37,1 & 2,04 \\
\hline \multicolumn{5}{|c|}{ Cambissolo Háplico Tb eutrófico típico (Santa Cruz da Baixa Verde - P2) } \\
\hline A & 126,1 & 122,7 & 31,4 & 1,75 \\
\hline Bi1 & 134,5 & 135,5 & 42,3 & 1,69 \\
\hline $\mathrm{Bi} 2$ & 152,0 & 146,9 & 42,3 & 1,76 \\
\hline $\mathrm{Bi} / \mathrm{Cr}$ & 144,3 & 163,4 & 44,3 & 1,50 \\
\hline \multicolumn{5}{|c|}{ Cambissolo Háplico Tb eutrófico latossólico (Triunfo - P3) } \\
\hline A & 129,8 & 150,9 & 71,4 & 1,46 \\
\hline $\mathrm{BA}$ & 152,0 & 144,2 & 55,8 & 1,79 \\
\hline Bi1 & 151,0 & 169,7 & 61,7 & 1,51 \\
\hline $\mathrm{Bi} 2$ & 144,3 & 181,8 & 71,1 & 1,35 \\
\hline $\mathrm{BC}$ & 133,5 & 166,4 & 64,8 & 1,36 \\
\hline
\end{tabular}


e um Latossolo Vermelho-Amarelo do Vale do Paraíba, observou resultados similares.

Melo et al. (1995b) também encontraram valores de $\mathrm{Ki}$ que indicavam a natureza caulinítica dos Cambissolos por eles estudados sobre embasamento cristalino (rochas graníticas), com elevados teores de Al na composição e condições ambientais de forte período chuvoso e relevo acidentado. Os valores de $\mathrm{Ki}$ encontrados nesse trabalho variaram entre 1,64 e 1,71; os valores de $\mathrm{SiO}_{2}$ e $\mathrm{Al}_{2} \mathrm{O}_{3}$ foram relativamente elevados em relação a $\mathrm{Fe}_{2} \mathrm{O}_{3}$, que apresentou valores bem mais baixos.

No presente trabalho os valores de $\mathrm{Fe}_{2} \mathrm{O}_{3}$ do ataque sulfúrico também foram baixos (Quadro 5), indicando a natureza mais sialítica dos materiais originários.

\section{Atributos mineralógicos}

Os difratogramas de raios $\mathrm{X}$ das frações areia e silte dos três perfis indicaram a presença de quartzo, feldspatos e anatásio (Quadro 6). O quartzo foi identificado pelos picos de difração no espaçamento basal de 0,426, 0,334, 0,24 e 0,182 nm; e o feldspato, pelos picos de $0,31,0,32,0,37,0,39,0,62$ e $0,67 \mathrm{~nm}$. De acordo com Oliveira et al. (2004), as diferentes posições dos picos indicam que mais de um tipo de feldspato está presente. Esses autores sugerem a predominância de feldspatos potássicos, uma vez que os picos na região de $0,32-0,31 \mathrm{~nm}$, além do pico de $0,66 \mathrm{~nm}$, estão sempre presentes. O anatásio foi identificado por meio dos picos de difração de 0,351 e $0,21 \mathrm{~nm}$. Resultados semelhantes foram encontrados por Mota et al. (2007), em Cambissolos da Chapada do Apodi (RN); por Oliveira et al. (2004), no Sertão do Araripe, PE; e por Corrêa et al. (2003), na região de Sousa (PB).
A mineralogia da fração argila é constituída por caulinita, principalmente, e por goethita e hematita, além de quartzo e feldspatos. A mica foi identificada no P1, ao longo do perfil. A caulinita foi identificada pela presença dos picos em 0,724, 0,357 e 0,45 nm e pelo desaparecimento dos picos após aquecimento a $550{ }^{\circ} \mathrm{C}$. A caulinita foi originada, provavelmente, a partir do intemperismo de feldspatos, presentes nas rochas, de acordo com a avaliação petrográfica.

Melo et al. (1995a), trabalhando com vários solos, inclusive Cambissolos, originados de embasamento cristalino (rochas graníticas) no Rio Grande do Sul, observaram a predominância de quartzo, caulinita, mica, goethita e rutilo na fração silte; e caulinita, mica, hematita e goethita na fração argila. Esses autores relataram que a presença de quartzo tanto na fração argila como nas frações mais grossas levou à liberação de sílica para a solução do solo, mesmo que lentamente, favorecendo a formação de caulinita.

O quartzo foi identificado na fração argila por meio dos picos de 0,426 e 0,334 nm, enquanto os feldspatos foram identificados pelos picos de 0,31 e 0,32 nm, notando-se a ausência do pico de $0,62 \mathrm{~nm}$, o qual está presente na areia e, em menor intensidade, no silte. Em outros estudos com solos da região semiárida também foi identificada a presença de quartzo e feldspatos na fração argila (Corrêa et al., 2003; Oliveira et al., 2004). Quando esse mineral ocorre em solos, normalmente se dá nas frações areia e silte, porém sabe-se que ele pode ocorrer na fração argila grossa e, em raros casos, na argila fina (Drees et al.,1989). O quartzo é oriundo das rochas do embasamento cristalino das áreas estudadas, que são essencialmente rochas sieníticas, com associações de rochas graníticas, especificamente no $\mathrm{P} 1$.

Quadro 6. Mineralogia das frações areia, silte e argila e do concentrado de óxidos de ferro dos solos (Qz: quartzo; Fd: feldspato; An: anatásio; Gt: goethita; Hm: hematita; Ct: caulinita; Mi/Ili: mica/ilita)

\begin{tabular}{|c|c|c|c|c|c|c|}
\hline Horizonte & Areia & Silte & Argila & $\begin{array}{l}\text { Concentração de } \\
\text { Óxidos }\end{array}$ & Saturação K Ar & $\begin{array}{c}\text { Saturação K } \\
550^{\circ} \mathrm{C}\end{array}$ \\
\hline $\begin{array}{l}\mathrm{A} \\
2 \mathrm{Bt} 1 \\
2 \mathrm{Bt} 2 \\
2 \mathrm{BC} \\
2 \mathrm{Cr}\end{array}$ & $\mathrm{Qz} ; \mathrm{Fd} ; \mathrm{An}$ & $\begin{array}{l}\text { Argissolo Ver } \\
\text { Qz; Fd; An }\end{array}$ & $\begin{array}{l}\text { ho-Amarelo d } \\
\text { Ct; Qz; Fd; } \\
\text { An; Gt } \\
\text { Ct; Qz; Fd; } \\
\text { An; Gt; Hm }\end{array}$ & $\begin{array}{l}\text { co abrúptico cambiss } \\
\text { Qz; Fd; An; Gt; } \\
\text { Hm }\end{array}$ & $\begin{array}{l}\text { (Serra Talhada - } \\
\text { Mi; Ili; Ct; Qz; } \\
\text { Fd; An }\end{array}$ & $\begin{array}{l}\mathrm{Mi} ; \mathrm{Ili} ; \mathrm{Qz} ; \mathrm{Fd} ; \\
\mathrm{An}\end{array}$ \\
\hline $\begin{array}{l}\mathrm{A} \\
\mathrm{Bi} 1 \\
\mathrm{Bi} 2 \\
\mathrm{Bi} / \mathrm{CR}\end{array}$ & $\mathrm{Qz} ; \mathrm{Fd} ; \mathrm{An}$ & $\begin{array}{l}\text { Cambissolo } \\
\text { Qz; Fd; An }\end{array}$ & $\begin{array}{l}\text { lico Tb eutró } \\
\text { Ct; Qz; Fd; } \\
\text { An; Gt; Hm }\end{array}$ & $\begin{array}{l}\text { jico (Santa Cruz da B } \\
\text { Qz; Fd; An; Gt; } \\
\text { Hm }\end{array}$ & $\begin{array}{l}\text { Verde - P2) } \\
\text { Ct; Qz; Fd; An }\end{array}$ & $\begin{array}{l}\text { Mi; Ili; Qz; Fd; } \\
\text { An }\end{array}$ \\
\hline $\begin{array}{l}\text { A } \\
\text { BA } \\
\text { Bi1 } \\
\text { Bi2 } \\
\text { BC }\end{array}$ & $\mathrm{Qz} ; \mathrm{Fd} ; \mathrm{An}$ & $\mathrm{Qz} ; \mathrm{Fd} ; \mathrm{An}$ & $\begin{array}{l}\text { issolo Háplic } \\
\text { Ct; Qz; Fd; } \\
\text { An; Gt; Hm }\end{array}$ & $\begin{array}{l}\text { utrófico típico (Triunf } \\
\qquad \begin{array}{l}\text { Qz; Fd; An; Gt; } \\
\text { Hm }\end{array}\end{array}$ & $\begin{array}{l}\text { Mi; Ili; Ct; Qz; } \\
\text { Fd; An } \\
\text { Ct; Qz; Fd; An }\end{array}$ & $\begin{array}{l}\text { Mi; Ili; Qz; Fd; } \\
\text { An }\end{array}$ \\
\hline
\end{tabular}


Conforme análise dos difratogramas, tanto da argila em pó, como do concentrado de óxidos, foram observados picos expressivos de goethita e hematita em todos os perfis estudados. A goethita foi identificada pelos picos de 0,418 e 0,244 nm, e a hematita, pelos picos de 0,269, 0,252 e 0,368 $\mathrm{nm}$. Observou-se, entretanto, que as maiores intensidades dos picos de difração da hematita ocorreram no P3, diminuindo em direção ao P1. Esse comportamento está condizente com os resultados das análises químicas, os quais mostram aumento do grau de evolução dos solos na direção de Serra Talhada para Triunfo, acompanhando o aumento da precipitação pluvial.

Também foi observado decréscimo na intensidade dos picos de difração, tanto da goethita como da hematita, com o aumento da profundidade do solo em todos os perfis. Com base nas análises petrográficas, provavelmente, o elemento ferro ainda está, predominantemente, associado aos minerais primários, sobretudo anfibólios e piroxênios, os quais apresentam alterações para óxidos e, ou, oxi-hidróxidos de ferro.

A presença dos picos de difração de 1,00, 0,50 e $0,33 \mathrm{~nm}$ indicou a presença de mica/illita, porém ocorrendo apenas ao longo do perfil P1 e no horizonte superficial de P3. Trata-se, provavelmente, de uma illita, a qual pode ser formada pelo intemperismo de feldspatos, com posterior precipitação em solução (Fanning et al., 1989). A presença desse mineral nesse solo coincidiu com os maiores níveis de $\mathrm{K}$ trocável (Quadro 4). Essa hipótese também pode ser reforçada pela ausência de mineral micáceo nas rochas estudadas (Quadro 7).

\section{Petrografia}

A petrografia das rochas formadoras do material de origem dos solos (Quadro 7) evidenciou pequenas diferenças quanto à sua composição e classificação. Todas as amostras fazem parte do mesmo batólito, sendo, provavelmente, oriundas do mesmo magma, motivo pelo qual algumas estão associadas. Todavia, a variação nos teores de um ou mais minerais acabou por diferenciá-las. As rochas do $\mathrm{P} 1$, que, devido à grande quantidade de fragmentos de rocha, teve material coletado em todos os horizontes, foram identificadas como quartzo-sienito (A), álcali-feldspatogranito (Bt1) e sienito (Bt2 e BC). No horizonte $\mathrm{Bi} / \mathrm{Cr}$ do P2 a rocha identificada foi anfibólio-quartzo-sienito, enquanto no P3 a amostra coletada no Bi2, único horizonte com fragmentos de rocha, foi identificada como sienito.

Essa constatação indica que o clima não foi o único fator que influenciou a diferenciação destes solos; o material de origem também imprime sua ação. A

\section{Quadro 7. Descrição simplificada das amostras de rochas retiradas dos perfis estudados}

\begin{tabular}{|c|c|c|c|}
\hline Perfil & Horizonte & Composição & Rocha \\
\hline & $\mathrm{A}$ & $\begin{array}{l}\text { microclina, pertita, minerais opacos (alguns euédricos, provavelmente magnetita, e outros } \\
\text { anédricos, nitidamente ligados à alteração de minerais primários - anfibólios e, ou, } \\
\text { piroxênios), quartzo (10 \%), anfibólios (em avançado estado de alteração), zircão e apatita. }\end{array}$ & $\begin{array}{l}\text { quartzo- } \\
\text { sienito }\end{array}$ \\
\hline \multirow[t]{3}{*}{$\mathrm{P} 1$} & $2 \mathrm{Bt} 1$ & $\begin{array}{l}\text { microclina, pertita, minerais opacos (alguns euédricos, provavelmente magnetita, e outros } \\
\text { anédricos, nitidamente ligados à alteração de minerais primários - anfibólios e, ou, } \\
\text { piroxênios), quartzo ( } 20 \%) \text {, titânita, zircão e apatita. }\end{array}$ & $\begin{array}{l}\text { álcali- } \\
\text { feldspato- } \\
\text { granito }\end{array}$ \\
\hline & $2 \mathrm{Bt} 2$ & $\begin{array}{l}\text { microclina, pertita, anfibólios ( } 5 \% \text {, em avançado estado de alteração, passando para } \\
\text { óxido/hidróxido de Fe) e zircão. }\end{array}$ & sienito \\
\hline & $2 \mathrm{BC}$ & $\begin{array}{l}\text { microclina, pertita, plagioclásio ( } 2 \% \text { ), anfibólio (uralita, proveniente da alteração hidrotermal } \\
\text { do piroxênio) e piroxênio, ambos mostrando alteração para óxido/hidróxido de Fe), quartzo (1 } \\
\text { \%), minerais opacos (alguns euédricos, provavelmente magnetita, e outros anédricos, produto } \\
\text { secundário dos minerais ricos em Fe), zircão, apatita. }\end{array}$ & sienito \\
\hline $\mathrm{P} 2$ & $\mathrm{Bi} / \mathrm{CR}$ & $\begin{array}{l}\text { microclina, pertita, plagioclásio (5 \%), anfibólio (15\%) e piroxênio, ambos mostrando alteração } \\
\text { para óxido/hidróxido de Fe), quartzo }(10 \%) \text {, minerais opacos, zircão, apatita. }\end{array}$ & $\begin{array}{l}\text { anfibólio- } \\
\text { quartzo- } \\
\text { sienito }\end{array}$ \\
\hline P3 & $\mathrm{Bi} 2$ & $\begin{array}{l}\text { feldspatos (altamente alterados para minerais de argila, porém mostrando contorno euédrico } \\
\text { característico, sendo possível também observar, localmente, em alguns grãos as clivagens e a } \\
\text { textura pertítica), piroxênios (euédricos a subédricos, mostrando claramente as clivagens } \\
\text { basais, ortogonais); também bastante alterados para óxido/hidróxido de Fe), zircão, titanita. } \\
\text { apesar de muito alterada, a ausência de quartzo e a alta porcentagem de pertita são indicativos } \\
\text { para a interpretação desta rocha como um sienito. }\end{array}$ & sienito \\
\hline
\end{tabular}


descrição demonstrou que existe variação nos teores de quartzo nas amostras, influenciando na textura dos solos estudados.

No caso do P1, a presença de minerais félsicos (principalmente quartzo) em quantidades variáveis, bem como o grau de intemperização variado dos materiais que o compõem, pode justificar os teores de areia mais elevados. Também a presença de pedaços de rochas arredondadas, tanto na superfície como ao longo do perfil, é indicativo de processos de transporte e deposição de material proveniente das partes mais altas do relevo. Agbenin \& Tiessen (1994), estudando uma topossequência em Serra Talhada, fizeram a mesma observação, ressaltando a abundância de fragmentos de rochas tanto na porção mediana quanto na porção mais baixa do relevo, demonstrando essa movimentação de material.

\section{CONCLUSÕES}

1. Os materiais de origem dos solos estudados são formados, predominantemente, por rochas sieniticas, tendo tido, pelo menos em parte, contribuição de materiais geológicos diferentes do substrato, provenientes das partes mais altas da paisagem, resultando em certa variação na natureza destes.

2. Foi constatado gradiente de evolução dos solos ao longo da topoclimossequência, com o aumento da precipitação pluvial, sendo o o perfil menos evoluído o de Serra Talhada (P1), e o mais evoluído, o de Triunfo (P3).

3. O clima, atuando, principalmente, pelo maior grau de umidade, não é o único fator de formação responsável pela variação dos solos ao longo da topoclimossequência, devendo-se ressaltar, também, a influência do material de origem e do relevo.

\section{AGRADECIMENTOS}

À CAPES, pela concessão da bolsa de mestrado, e ao $\mathrm{CNPq}$, pelo financiamento da pesquisa e concessão de bolsa de produtividade em pesquisa.

\section{LITERATURA CITADA}

AGBENIN, J.O. \& TIESSEN, H. Phosphorus along a semiarid tropical catena. Geoderma, 62:345-362, 1994.

ANDRADE, H.; SCHAEFER, C.E.; DEMATTÊ, J.L.I. \& ANDRADE, F.V. Pedogeomorfologia e micropedologia de uma sequência Latossolo - areia quartzosa hidromórfica sobre rochas cristalinas do estado do Amazonas. Geonomos, 5:55-66, 1997.
ANDRADE-LIMA, D. Estudos fitogeográficos de Pernambuco. Arq. Inst. Pesq. Agron. Pernambuco, 5:305-341, 1960.

ANDRADE-LIMA, D. Esboço fitoecológico de alguns "brejos" de Pernambuco. B. Técnico. Inst. Pesq. Agron. Pernambuco, 8:3-9, 1966.

ANDRADE-LIMA, D. Present day forest refuges in Northeastern Brazil. In: PRANCE, G.T., ed. Biological diversification in the tropics. New York, Columbia University Press, 1982. p.245-254.

ARAÚJO, M.S.B.; SCHAEFER, C.E.R. \& SAMPAIO, E.V.S.B. Soil phosphorus fractions from toposequences of semiarid Latosols and Luvisols in northeastern Brazil. Geoderma, 119:309-321, 2004.

BAYER, C. \& MIELNICZUK, J. Dinâmica e função da matéria orgânica. In: SANTOS, G.A. \& CAMARGO, F.A.O., eds. Fundamentos da matéria orgânica do solo: Ecossistemas tropicais e subtropicais. Porto Alegre, Gênesis, 1999. p.926.

BRASIL. Ministério da Agricultura. Levantamento exploratório-reconhecimento de solos do Estado de Pernambuco. Recife, Convênio MA/DNPEA-SUDENE/ DRN, 1972. v.2. 354p. (Boletim Técnico, 26)

BUOL, S.W.; HOLE, F.D. \& MC CRACKEN, R.J. Soil genesis and classification. Iowa, Iowa State University Press, 1973. 360 p.

CORRÊA, M.M.; KER, J.C.; MENDONÇA, E.S.; RUIZ, H.A. \& BASTOS, R.S. Atributos físicos, químicos e mineralógicos de solos da região das Várzeas de Sousa (PB). R. Bras. Ci. Solo, 27:311-324, 2003.

CORRÊA, M.M. Óxidos de ferro e tipificação de caulinitas na gênese de solos coesos do ambiente dos Tabuleiros Costeiros. Viçosa, MG, Universidade Federal de Viçosa, 2005. 194p. (Tese de Doutorado)

DREES, L.R.; WILDING, L.P.; SMECK, N.E. \& SENKAYI, A.L. Silica in soils: Quartz and disordered Silica Polymorphs. In: DIXON, J.B. \& WEED, S.B. Minerals in soil environments. 2.ed. Madison, SSSA, 1989. p.913-974.

EMPRESA BRASILEIRA DE PESQUISA AGROPECUÁRIA EMBRAPA. Manual de métodos de análise de solo. Rio de Janeiro, Centro Nacional de Pesquisa de Solos, 1997. $212 \mathrm{p}$.

EMPRESA BRASILEIRA DE PESQUISA AGROPECUÁRIA EMBRAPA. Sistema brasileiro de classificação de solos. 2.ed. Rio de Janeiro, Embrapa Solos, 2006. 306p.

FANNING, D.S.; KERAMIDAS, V.Z. \& EL-DESOKY, M.A. Micas. In: DIXON, J.B. \& WEED, S.B., eds. Minerals in soil environments. 2.ed. Madison, Soil Science Society of America, 1989. p.512-634.

FERRAZ, E.M.N. \& RODAL, M.J.N. Caracterização fisionômica - estrutural de um remanescente de floresta ombrófila montana de Pernambuco, Brasil. Acta Bot. Bras., 20:911926, 2006

FERREIRA, V.P. \& SIAL, A.N. The peralkalic magmatism in the Precambrian cachoeirinha-salgueiro foldbel, northeast Brazil: Geochemical aspects. R. Bras. Geoci., 16:73-85, 1986. 
KÄMPF, N. \& SCHWERTMANN, U. The 5 M-NaOH concentration treatment for iron oxides in soils. Clays Clay Miner., 30:401-408, 1982.

LINS, R.C. As áreas de exceção do agreste de Pernambuco Recife, Sudene, 1989.

MEKARU, T. \& UEHARA, G. Anion adsorption in ferruginous tropical soils. Soil Sci. Soc. Am. Proc., 36:296-300, 1972.

MELFI, G.P. \& VOLKOFF, B. Natureza e distribuição dos compostos ferríferos nos solos do Brasil. R. Bras. Ci. Solo, 3:47-54, 1979.

MELO, V.F.; COSTA, L.M.; BARROS, N.F.; FONTES, M.P.F. \& NOVAIS, R.F. Reserva mineral e caracterização mineralógica de alguns solos do Rio Grande do Sul. R. Bras. Ci. Solo, 19:165-171, 1995a.

MELO, V.F.; BARROS, N.F.; COSTA, L.M.; NOVAIS, R.F. \& FONTES, M.P.F. Formas de potássio e magnésio em solos do Rio Grande do Sul e sua relação com o conteúdo na planta e com a produção em plantios de eucalipto. $R$. Bras. Ci. Solo, 19:159-164, 1995b.

MENEZES, R.S.C.M.S.; GARRIDO, A.M. \& PEREZ, M. Fertilidade dos solos no Semi-Árido. In: CONGRESSO BRASILEIRO DE CIÊNCIA DO SOLO, 30., Recife, 2005. Anais. Recife, 2005. CD-ROM.

MIELNICZUK, J. Formas de potássio em solos do Brasil. R. Bras. Ci. Solo, 1:55-61, 1977.

MOTA, J.C.A.; ASSIS JÚNIOR, R.N.; AMARO FILHO, J.; ROMERO, R.E.; MOTA, F.O.B. \& LIBARDI, P.L. Atributos mineralógicos de três solos explorados com a cultura do melão na Chapada do Apodi - RN. R. Bras. Ci. Solo, 31:445454. 2007.

MURPHY, C.P. Thin section preparation of soils and sediments. Berkhanmsterd, Academic Publis., 1986. 145p.

OLIVEIRA, L.B.; RIBEIRO, M.R.; FERRAZ, F.B. \& JACOMINE, P.K.T. Classificação de solos Planossólicos do Sertão do Araripe (PE). R. Bras. Ci. Solo, 27:685-693, 2003.
OLIVEIRA, L.B.; RIBEIRO, M.R.; FERRAZ, F.B.; FERREIRA, M.G.V.X. \& MERMUT, A.R. Mineralogia, micromorfologia e gênese de solos Planossólicos do Sertão do Araripe, Estado de Pernambuco. R. Bras. Ci. Solo, 28:665-678, 2004.

RODAL, M.J.N.; SALES, M.F.; SILVA, M.J. \& SILVA, A.G. Flora de um Brejo de Altitude na escarpa oriental do planalto da Borborema, PE, Brasil. Acta Bot. Bras., 19:843858, 2005.

RUIZ, H.A. Incremento da exatidão da análise granulométrica do solo por meio da coleta da suspensão (silte + argila). $R$. Bras. Ci. Solo, 29:297-300, 2005.

SANTOS, R.D.; LEMOS, R.C.; SANTOS, H.G.; KER, J.C. \& ANJOS, L.H.C. Manual de descrição e coleta de solo no campo. 5.ed. Viçosa, MG, Sociedade Brasileira de Ciência do Solo, 2005. 100p.

SILVA, F.A.B.; HERNÁNDEZ, M.I.M.; IDE, S. \& MOURA, R.S. Comunidade de escarabeíneos (Coleoptera, Scarabaeidae) copro-necrófagos da região de Brejo Novo, Caruaru, Pernambuco, Brasil. R. Bras. Entomol., 51:228-233, 2007.

SINGH, B. \& GILKES, R.J. Concentration of iron oxides from clays by $5 \mathrm{M} \mathrm{NaOH}$ : the complete removal of sodalite and kaolin. Clays Miner., 26:463-472, 1991.

TABARELLI, M. \& SANTOS, A.M.M. Uma breve descrição sobre a história natural dos brejos nordestinos In: PORTO, K.C.; CABRAL, J.J.P. \& TABARELLI, M., orgs. Brejos de altitude em Pernambuco e Paraíba; História natural, ecologia e conservação. Brasília, Ministério do Meio Ambiente, 2004. p.227-284.

VERDADE, F.C. Análise química total. In: MONIZ, A.C., ed. Elementos de pedologia. São Paulo, EDUSP, 1972. p.209221.

WHITTING, L.D. \& ALLARDICE, W.R. X-ray diffraction techniques. In: KLUTE, A., ed. Methods of soil analysis; Physical and mineralogical methods. Madison, Soil Science Society of America, 1986. Part 1. p.331-359. 